Revista Científica de FAREM-Estelí

Medio ambiente, tecnología y desarrollo humano

Año 10 | Edición especial: artículos de revisión documental

ISSN: 2305-5790

https://rcientificaesteli.unan.edu.ni

DOI: https://doi.org/10.5377/farem.v0i0.11605

\section{El concepto de juventud: una mirada desde la perspectiva generacional}

\section{The concept of youth: A view from a generational perspective}

\section{Pablo David Yup de León}

Instituto Universitario en Democracia, Paz y Seguridad -IUDPAS-

Universidad Nacional Autónoma de Honduras

https://orcid.org/0000-0002-8470-3365

pablo.yup@unah.edu.hn

\section{María Dolores Álvarez Arzate}

Universidad Nacional Autónoma de Nicaragua, Managua

https://orcid.org/0000-0002-6836-1318

malvarez@unan.edu.ni

\section{RESUMEN}

En el presente artículo se hace una revisión teórica del concepto de juventud desde la perspectiva generacional con el objetivo de conocer las diferentes conceptualizaciones de las juventudes vistas como parte de una generación global y Glocal en el contexto latinoamericano y centroamericano. Las fuentes utilizadas para la obtención de la información se basaron en la revisión de los repositorios de la Universidad Nacional Autónoma de Nicaragua (UNAN-Managua) y Universidad Nacional Autónoma de Honduras (UNAH), por medio de los sistemas de bases de datos de bibliografía científica como Ebsco, Sage, Google Académico y la base de datos externa Taylor and Francis Online. La actual generación de jóvenes, llamada "generación Glocal", vive en un mundo globalizado, de sobremodernidad, donde convergen la lógica del consumo, la tecnología, el internet y el acceso a la información sin precedentes. Las juventudes, como diría Mannheim, están influenciadas por su entorno socio histórico e impactan en las generaciones futuras, por ello es importante analizar las dinámicas que influyen en sus experiencias, así como las formas de adaptarlas a lo cotidiano, a lo Glocal y sus expresiones en espacio público en la primera década y sus proyecciones hacia la naciente segunda década del Siglo XXI.
RECIBIDO

$26 / 03 / 2021$

ACEPTADO

19/052021
PALABRAS CLAVE

Juventud; generaciones; Glocal. 


\section{ABSTRACT}

In this article a theoretical review of the concept of youth from a generational perspective is made with the objective of knowing the different conceptualizations of the youth seen as a part of the global and Glocal generation in the Latin and Central American context. The sources used to obtain the information were based on the rewiew of the repositories of the National Autonomous University of Nicaragua (UNAN-Managua) and the National Autonomous University of Honduras (UNAH), through the scientist bibliography database systems such as Ebsco, Sage, Google Academic and the external database Taylor and Francis online. The current generation of the young people, called the "Glocal generation" lives in a globalized world, of overmodernity, where the logic of consumption, technology, the internet and unprecedented access to information converge. Youth, as Mannheim would say, are influenced by their socio-historical environment and have an impact on future generations, therefore it is important to analyze the dynamics that influence their experiences, as well as the ways to adapt them to everyday, to the Glocal and their expressions in public space in the first decade and their projections towards the emerging second decade of the XXI century.

\section{KEYWORDS}

Youth; generations; Glocal. 


\section{INTRODUCCIÓN}

El presente artículo científico se escribe como parte de las investigaciones del doctorado en Gestión y Calidad de la Investigación Científica de la Universidad Nacional Autónoma de Nicaragua, Managua (UNAN-Managua) en la sede de la Facultad Regional Multidisciplinaria de Estelí.

El tema a abordar está centrado en la categoría juventud desde diferentes perspectivas tanto institucionales como académicas. Se exponen los criterios de autores clave acerca de los términos de generación, globalización y acceso a tecnologías, así como Glocalización y generación Glocal. Se discuten los diversos enfoques para desarrollar una mirada desde la perspectiva generacional.

Iniciamos diciendo que la juventud, como criterio de edad cronológica, dicho por Bourdieu, es al mismo tiempo una construcción social, histórica, cultural y relacional que a través de las diferentes épocas y procesos históricos y sociales ha ido adquiriendo denotaciones y delimitaciones diferentes. (1984/2003, pág. 164)

Y por ello, Doutor argumenta que "la juventud debe ser abordada desde la heterogeneidad, (...) como una realidad construida socialmente en la que se pueda obtener diferentes miradas, a partir de las condiciones culturales, sociales, económicas y políticas" ${ }^{\prime \prime}$. (2016, pág. 161)

Ahora bien, una generación en palabras de Ortega y Gasset, es conocer la realidad desde la perspectiva de quien la vive, desde el sujeto que la vive. (1951, págs. 30-31)

Mannheim afirma que la juventud es "un sujeto colectivo con una visión del mundo en particular, capaz de o inclinado a actuar por su cuenta y sus propios intereses particulares". (1928/2007, pág. 221)

En tanto, Bauman retoma el concepto de Mannheim añadiendo que la generación "en el sentido de totalidad, destaca por los rasgos comunes de todas las unidades que la forman y que no se pueden encontrar en ningún otro lugar". (2007, pág. 121)

En el actual contexto de un mundo globalizado, de sobremodernidad, de no lugares y de lo virtual en palabras de Augé, la humanidad en general y la juventud en particular tienen un exceso de información, de imágenes y de individualismo. "Estos excesos dan la sensación que el tiempo y la historia se aceleran, que el planeta se encoge y que el individuo se vuelve pasivo" (2009, pág. 6). 
En este entorno donde se entrecruzan espacio, individuo e historia convergen simultáneamente el consumismo, la tecnología, el internet y el acceso a la información sin precedentes, el "ser joven" ha cambiado su significación en tanto se encuentran inmersos en estas dinámicas.

Bajo estas premisas surge la categoría de "generación Glocal" como explica Ramírez. Esta nueva clasificación de la juventud permite integrar los actuales cambios que promueve la tecnología, los nuevos modos de interacción entre lo global y lo local y viceversa. Este enfoque centrado en los jóvenes reconoce y comprende los cambios en las formas de participación que introducen elementos culturales propios de la generación y los adaptan a su participación social (2020, págs. 9-13).

A la luz de la perspectiva científica externa se crea la categoría "generación Glocal" pero ellos, los protagonistas, ¿̇se auto identifican como tales, poseen esas características y las ejercen en lo global y en lo Glocal? Esa es la reflexión del presente artículo.

\section{MATERIALES Y MÉTODOS}

Los materiales considerados fueron de carácter bibliográfico, es decir que se hizo una búsqueda enfocada en el tema de juventud, generación, globalización, acceso a las tecnologías, Glocalización y generación Glocal.

El método empleado fue el análisis de contenido y los pasos metódicos fueron: 1. Delimitar el tema de estudio; 2 . Búsqueda de la información en las bases de datos a partir de palabras clave; 3. Selección de autores; 4. Selección de citas; 5 . Clasificación y agrupación de conceptos por sus coincidencias; y 6. Organización del material para el desarrollo de los argumentos, discusión y conclusiones del artículo.

\section{RESULTADOS}

\section{Aproximaciones al concepto de juventud}

Definiendo la juventud sólo como un grupo etario hay divergencias entre países, instituciones e incluso entre las diferentes organizaciones de Naciones Unidas como lo señala Krauskopf (2015, pág. 123). 
Existe una invisibilidad de los jóvenes por ejemplo en la Convención Internacional de los Derechos del Niño se hace referencia implícita a la juventud incluyéndose en la niñez hasta los 18 años. (UNICEF, 2006, pág. 6)

Para 1985 las Naciones Unidas designa el Año Internacional de la Juventud y adopta el límite etario para los jóvenes entre 15 a 24 años. (ONU, 1979; UNESCO, 1985, pág. 42)

Tanto para la conmemoración del 25 aniversario del Año Internacional de la Juventud, como las declaraciones del día internacional de la juventud, Naciones Unidas sigue definiendo a la juventud demográficamente como grupo etario que incluye a personas entre los 15-24 años. (ONU, 2009)

De acuerdo a las fases de desarrollo infantil de Piaget, nos interesa la cuarta fase o etapa de las operaciones formales que se inicia desde los doce años hasta la adultez. Es la etapa del pensamiento abstracto, no solo (el joven) piensa la realidad, sino cómo puede hacer las cosas, ya puede hipotetizar, esta etapa es alcanzada por la mayoría de jóvenes, pero hay algunos que no lo logran. (1969/1997, pág. 151)

Sin embargo, el concepto de juventud delimitado por la edad no es universal como lo apunta Reguillo, "hoy sabemos que las distintas sociedades en diferentes etapas históricas han planteado las segmentaciones sociales por grupos de edad de muy distintas maneras y que, incluso, para algunas sociedades este tipo de recorte no ha existido". (2003, pág. 104)

El concepto de juventud en las ciencias sociales se ha abordado desde el punto de vista etario, sin embargo, esta aproximación confiere homogeneidad a los jóvenes sin hacer distinción entre quienes viven en la ciudad, en el campo, pertenecen a poblaciones indígenas, afrodescendientes o con aquellos que viven en las marginalidades, para citar las particularidades más notorias.

A nivel regional, en Centroamérica contamos con el Informe Nacional sobre Desarrollo Humano, 2011 "Las juventudes construyendo Nicaragua", en donde se evalúan factores objetivos y subjetivos que dan como resultado una "enorme diversidad entre adolescentes y jóvenes del campo y la ciudad, pertenecientes a etnias y razas distintas hombres y mujeres, -con opciones sexuales y en edades diferentes-, puede transformarse en fuente de desigualdad, exclusión y pobreza si no se reconoce y valora". (2011, pág. 12)

En este informe se reconoce la diversidad de la juventud y sus diferencias sin embargo el rasgo demográfico sigue predominando al afirmar que (los jóvenes) "son el resultado de normas, representaciones culturales y reglas definidas por la sociedad en contextos históricos y socioculturales específicos, a partir de una base biológica y cronológica". (2011, pág. 47) 
En dicho estudio se llega a la conclusión de que se debe hablar de juventudes dado que estas varían según el tiempo, el área geográfica, las relaciones sociales e históricas, la construcción de género, la etnia y la influencia de la globalización. (2011, pág. 47)

En este mismo orden de ideas se define la juventud en Guatemala, como una categoría histórica, heterogénea, influenciada por el contexto político, económico y social que delimitan el papel social diferenciado que desempeñan en la sociedad. (CEG, 2012, pág. 13)

En El Salvador se aborda la juventud como una heterogeneidad, al reconocer que "no es lo mismo ser un hombre joven con escolaridad superior residente del área metropolitana, que una mujer joven de baja escolaridad residente del área rural de un departamento de la zona norte". (PNUD, 2018, pág. 53)

El mismo informe afirma que "el contexto y las oportunidades son determinantes en esta etapa del ciclo de vida. Lo que una persona adolescente o joven puede o no hacer, no solo depende de su voluntad y esfuerzo, sino también de cómo la sociedad configura y provee las oportunidades, y organiza su régimen de bienestar". (2018, pág. 53)

Para Bourdieu, "la juventud y la vejez no están dadas, sino que se construyen socialmente en la lucha entre jóvenes y viejos" (1990, pág. 164). El mismo autor refiere que el concepto de juventud es una construcción social, histórica, cultural y relacional, que a través de las diferentes épocas y procesos históricos y sociales han ido adquiriendo denotaciones y delimitaciones diferentes. (1984/2003, pág. 164)

En este mismo orden de ideas los jóvenes, afirma Brito Lemus, sostienen una lucha constante con respecto al poder, que está relacionada con la posición socioeconómica, la auto identificación étnica, sexual y de género que engloba el componente histórico con significados específicos para su generación, los cuales han sido construidos socialmente con imágenes propias que auto identifican y dan valor al "individuo" y "al estar en el mundo" y su integración en la sociedad. (2002, pág. 57)

Continua Brito Lemus y afirma que "lo juvenil adquiere significación a partir del momento en que se establece una diferenciación cultural con los demás sujetos sociales" (2002, pág. 44).

Significa que, esta diferenciación va más allá de los aspectos biológicos o etarios y es una lucha con los demás integrantes de la sociedad con el fin de sobresalir y obtener reconocimiento social.

Por su parte Dávila considera que el concepto de juventud tiene dos componentes: lo juvenil y lo cotidiano. El primero, hace alusión a las características psicosociales en la construcción de la identidad del joven; 
segundo, son las relaciones y prácticas sociales en donde actúa lo juvenil con los elementos del contexto. (2004, pág. 92)

Afirma Pérez Islas que en la conformación del proceso de juventud existe una contradicción fundamental en tanto que el joven está preparado biológica y psicológicamente para ejercer su papel en la sociedad y esta no le permite realizarlo sin antes normarlo. Desde un punto de vista institucional, el joven adquiere un estatus de indefinición y de subordinación, es decir, se le prepara y forma para el futuro no para el presente. (2000, págs. 200-201)

En sus estudios sobre los jóvenes en los espacios públicos, Reguillo considera que han sido enviados al silencio, por no pertenecer al "nosotros", por ser diferentes, para acallarlos. (2000, pág. 75)

Así Reguillo señala que "ser joven" no es un dato que se agota con la acumulación biológica de años. El "ser joven" es una clasificación social que supone el establecimiento de un sistema (complejo) de diferencias. (2008, págs. 11-13)

El desafío estriba, de acuerdo con Reguillo, en atender los procesos que modelan y modulan la condición juvenil para reconocer lo que tienen de común -de cara a los procesos de globalización-, y lo que tiene de especificidad, -de cara a la densidad de las memorias y culturas locales-". (2008, págs. 11-13)

En esta línea de pensamiento coincide Chaves y explica que la juventud solo cobrará sentido analítico si se aborda desde las particularidades del mundo social; es en este mundo social, donde se encontrará el sentido de ser o estar joven de acuerdo a su auto y hetero percepción que llamaremos juventudes. (2006, pág. 15)

Se han planteado las más importantes aproximaciones al concepto de juventud, tanto las originadas en las organizaciones internacionales, regionales como las de carácter académico.

Encontramos que el concepto juventud abarca criterios demográficos y los relacionados con la construcción social de cada cultura, contexto y circunstancias que le dan sentido.

De igual forma la definición y uso del concepto juventud estará vinculado con la perspectiva de quién lo construye, ya sean visiones juveniles o por el contrario visiones adultistas. También influyen las condiciones sociales, económicas, históricas, políticas de estas personas que buscan reconocimiento, visibilidad social y equidad en su integración en la sociedad, economía y vida política, entre las más relevantes. 
Debido a la heterogeneidad de los diferentes pensamientos que definen "juventud" es que se propone plantear "juventudes" en plural en la medida que la visión amplia es a la vez la más integradora de una amplia diversidad de perspectivas.

\section{Generación}

Se toma como punto de partida la definición de Mannheim, quien se refiere a los aspectos que conforman una generación como la posición generacional, conexión generacional, unidad generacional y estratificación de la vivencia. (1928/2007, pág. 221)

Primero, en la posición generacional, describe Mannheim, hay un componente biológico, en demografía se refiere a los cambios en la estructura y composición de la población como la vida, la muerte y la edad. Además, se comparte una corriente histórica con formas determinadas de vivencias, experiencias y pensamientos que forman una comunidad. Esa conexión generacional es el vínculo entre los individuos de una posición generacional con el contexto histórico y su participación activa o pasiva en ese contexto. (1928/2007, pág. 208)

Segundo, la conexión generacional puede existir diversas concepciones acerca de una misma problemática, incluso pueden ser opuestas. (Ibidem, 1928/2007, pág. 209)

Tercero, el motor diferenciador de las unidades generacionales está comprendido por las relaciones que vinculan a las personas o individuos con el grupo, el efecto socializador, es como un "un agitarse juntos". (Ibidem, 1928/2007, pág. 225)

Cuarto, la estratificación de la vivencia, que consiste en la formación de la conciencia, principalmente por las vivencias o experiencias de las primeras impresiones durante la juventud de tal forma que las subsiguientes están condicionadas por esa primera impresión. Para Mannheim las experiencias no se acumulan, sino que se articulan de manera dialéctica (Ibidem, 1928/2007, pág. 227).

Desde el punto de vista de Mannheim, las personas están influenciadas por su entorno socio histórico de tal manera que dos generaciones (cohortes de edades) distintas pueden vivir en un mismo contexto histórico, pero con distintas perspectivas y lo que para una generación no fue problemático para la otra sí. Esto explica las dificultades de origen que tiene la conflictividad entre grupos generacionales. 


\section{Globalización y acceso a las tecnologías}

Sin entrar a profundizar el término de globalización, adoptamos la definición propuesta por Giddens, como "el proceso que vincula las relaciones sociales globales que unen lo local, por muy distante que se encuentre el lugar, este se encuentra influenciado por los hechos que se desarrollan en otros puntos del planeta". (1990, pág. 64)

El mismo autor afirma que este proceso de interacción que ocurre entre lo global y lo local, puede retroalimentarse y ser de dos vías, es así que la transformación de lo local forma parte de lo global como una extensión de las relaciones sociales a través del tiempo y espacio. (Ibidem, 1990, pág. 64)

En este contexto de mundo globalizado, de sobremodernidad, de no lugares y de lo virtual, en palabras de Augé, estos elementos tienen un exceso de información, de imágenes y de individualismo. "Estos excesos dan la sensación que el tiempo y la historia se aceleran, que el planeta se encoge y que el individuo se vuelve pasivo". (2009, pág. 6)

En esta misma línea de ideas, Homobono afirma que la globalización "lejos de abocar a una convergencia cultural, paradóiicamente puede incrementar la producción de diversidad, la contestación y la reafirmación de las identidades de los grupos socioculturales y de las culturas locales en el interior de los Estados nacionales". (2019, pág. 21)

Estas ideas se contraponen a la creencia de que la globalización implica el declive de lo local, al contrario, estos elementos se complementan, es así que éste "fenómeno que transforma la relación entre el lugar de la vivencia y la cultura, se le ha llamado desterritorialización, que no elimina lo vivido localmente sino que incorpora nuevos elementos globalizadores. A esta dialéctica se le ha llamado Glocalización". (Homobono, 2019, pág. 22)

De tal manera que, este entorno donde se entrecruzan espacio, individuo e historia convergen simultáneamente el consumismo, la tecnología, el internet y el acceso a la información sin precedentes, el "ser joven" ha cambiado su significación en tanto se encuentran inmersos en estas dinámicas.

Así mismo, Martín-Barbero advertía el surgimiento de un ecosistema comunicativo diferente, que consiste en el uso cotidiano de las tecnologías que producen nuevas formas de sentir y percibir el espacio y el tiempo, de escuchar y ver, y que choca con el sensorium de los adultos. (2014, pág. 106)

En palabras de Muñoz, estamos en presencia de un nuevo sujeto, de otras subjetividades, de otras formas o maneras de consolidar la propia experiencia, de otros regímenes de formación del yo, de otras maneras de relacionar el mundo y los demás mediados por las tecnologías de información. (2010, pág. 28) 
Del mismo modo Rueda afirma que surge "un nuevo sujeto heterogéneo y complejamente conexo a un entorno múltiple: inmediato y virtual, selectivo y masivo, local y global, posicional y nómada al mismo tiempo". (2003, pág. 40)

Feixa explica de manera crítica que a partir de 2011 se vislumbra un nuevo sujeto, el del lumpen proletariado de la era moderna, jóvenes hiperformados e hiperinformados y sin embargo, precarizados, conectados por medio de redes sociales y que a veces reaccionan de forma creativa y pacífica y otras en forma airada y violenta. (2018, pág. 98)

Desde esta perspectiva Reguillo señala que en nuestros contextos latinoamericanos, "existen claramente dos juventudes: una, mayoritaria, precarizada, desconectada (...) sobreviviendo apenas con los mínimos, y otra, minoritaria, conectada, incorporada a los circuitos e instituciones de seguridad y en condiciones de elegir". (2010, pág. 432)

En consecuencia, Reguillo incluye un nuevo término, el de precarización subjetiva, que se refiere a la "dificultad del joven para pronunciarse con certeza sobre sí mismo, la experiencia límite de la incertidumbre y desconfianza en las propias capacidades, la contingencia como el eje que organiza la vida diaria. El único recurso a mano es el presente". (Ibidem, 2013, pág. 141)

A esto se suma lo que ocurre actualmente con la pandemia del Covid 19 y los posibles impactos que tendrá en la juventud. Entre ellos el confinamiento involuntario, el miedo al contagio, el traslado del espacio público al interior de los hogares, incrementando el uso de las redes sociales. (de la Torre, 2020, págs. 151-157)

En síntesis, las tecnologías relacionadas al internet, las redes sociales y lo virtual han creado un nuevo sensorium, nuevas maneras de ver, sentir y percibir el mundo, que se conecta con lo global y piensa en lo Glocal. En nuestra realidad latinoamericana y centroamericana, principalmente, la tecnología está creando mundos paralelos y diferentes para la juventud, uno donde una parte tiene el acceso a estas tecnologías y otra, donde la situación es precaria, desigual y el acceso (a las tecnologías) es limitado.

\section{Glocalización y Glocal}

La noción de Glocalización, según Robertson, es "parte de la globalización, como la convergencia de lo global y lo local, integrando espacio y tiempo. La forma de la globalización se reconfigura de manera reflexiva, es decir, que la Glocalización es el rango constitutivo de la globalización contemporánea". (2000, pág. 22)

Actualmente, la Glocalización es el término que se utiliza para describir la interacción entre lo "local" y lo "global". "Este vocablo proviene originalmente 
del japonés "dochakuka" que significa cómo un agricultor adopta técnicas de producción a sus condiciones locales". (Robertson, 2000, pág. 5)

En este marco de referencia, Acevedo y Correa argumentan que el encuentro de las realidades virtuales modifica la estructura social cambiando a los actores sociales en lo individual haciéndoles suponer que son parte del mundo y que lo que pase en cualquier parte del mismo, le afecta individual y colectivamente, esto es llamado la dependencia Glocal. (2016, pág. 209)

En otras palabras, la Glocalización, como expresión de la globalización, es la interacción entre lo local y lo global; siendo lo local, un sujeto, un grupo, una comunidad, una cultura o un Estado. Esta interacción puede darse en dos vías, que al mismo tiempo se contradicen y se complementan. Haciendo pensar al local que forma parte de lo global, aun cuando este se encuentre a larga distancia del evento.

En este contexto, el horizonte de lo Glocal nos ubica en el espacio de interacción entre lo diverso y heterogéneo de la realidad, lo social y sus relaciones, contradicciones, que pueden crear oportunidades de compartir e identificar nuevas fronteras, nuevas contradicciones². (Sedda, 2015, pág. 57)

Lo Glocal ayuda a los jóvenes a expresarse en el escenario mundial, a abrir nuevos horizontes por medios virtuales a diversas aspectos políticos, económicos o de entretenimiento ${ }^{3}$. (Gabsi, 2020, pág. 22)

En palabras de Feixa y Nilan, la juventud global, debe ser comprendida como el colectivo híbrido -tanto en lo local como internacional-, que construye sus espacios influenciados por culturas, consumos, contextos y digitalismo globales. (2009, pág. 81)

En tanto que la "generación Glocal" presenta particulares en que los jóvenes adaptan elementos globalizadores y los apropian a sus realidades locales. (Ramírez, 2020, pág. 9)

Al mismo tiempo, la generación Glocal posee tres características a considerar: la cultura Glocal, la ciudadanía Glocal y lo virtual. La primera, por cultura Glocal se comprende el cambio en las maneras de participación o involucramiento de los jóvenes que introducen elementos culturales específicos de la generación que van más allá de lo informal y que se adaptan en las estructuras de la participación social. (Ramírez, 2020, pág. 11)

La segunda característica, la ciudadanía Glocal está relacionada con los elementos básicos de que los individuos son sujetos de derechos y deberes. Esta generación expresa su ciudadanía que participa en los entornos locales, pero se expresa globalmente. (Ramírez, 2020, pág. 12) 
La tercera característica, lo virtual se desarrolla por la introducción de las nuevas tecnologías, se correlaciona con las nuevas formas de comunicación y de información, y su expresión más desigual es la brecha digital que transforma la juventud y profundiza el analfabetismo digital. (Ramírez, 2020, págs. 12-13)

Esta nueva clasificación de la juventud como "Glocal" permite integrar los actuales cambios que promueve la tecnología, los nuevos modos de interacción entre lo global y lo local y viceversa. Este enfoque centrado en los jóvenes reconoce y comprende que los cambios en las formas de participación introducen elementos culturales propios de la generación y los adaptan a su participación social.

Otra característica de esta generación Glocal es su involucramiento en el respeto de sus derechos y obligaciones desde un entorno local y que se expresa globalmente con otros jóvenes de otras partes.

Asimismo, la incorporación de lo virtual que se manifiesta en las nuevas formas de comunicación y de información, permitiendo que los jóvenes se conecten con el mundo, pero de manera desigual. Aunque pertenezcan a esta generación Glocal la mayor parte de los jóvenes tiene limitado acceso a las nuevas tecnologías conociéndose este hecho como la brecha digital o analfabetismo digital.

En este espacio encontramos que la juventud es heterogénea, diversa, múltiple y que es limitado abordarla desde una perspectiva etaria. Que este colectivo tiene una memoria y una cultura propia que se construye en sus espacios de interacción por medio de redes sociales informales incluyendo las presenciales y virtuales.

Los jóvenes tienen sus propias identidades y sus propios contextos, sus propios intereses, esto les permite poseer diferentes auto y heteropercepciones de sí mismos y hacia los demás, con significados diversos y complejos.

Sin embargo, las visiones adultistas que predominan en las instituciones se trata de encasillar a los jóvenes sin considerar que la noción de juventudes es una construcción social y relacional que varía en el tiempo.

Una de las formas de conocer a una generación es verla desde el punto de vista de quien la vive, de quien pertenece a ella, de quien se autoidentifica como tal. El concepto de generación tiene un componente histórico de grupos que comparten vivencias, experiencias y pensamientos de una comunidad, es así que estos modos, estas formas, estas maneras crean a las generaciones, pero que no son iguales para todos. 
Cada generación construye sus propios significados, sus propias estructuras de sentido, que a su vez difieren con la anterior provocando rupturas y distanciamientos que pueden llegar a ser irreconciliables.

Desde otra perspectiva, la globalización permite desarrollar relaciones sociales a nivel global que acercan a las comunidades desde la instantaneidad del mundo virtual a pesar de las distancias físicas, no obstante, persisten las limitaciones económicas y de conectividad en el acceso a las tecnologías de información.

En lo que respecta a la tecnología y la juventud, hay un nuevo "ecosistema comunicativo" y son los jóvenes quienes mejor se han adaptado a la introducción y los cambios de la tecnología, creando nuevas formas de experimentar el espacio y el tiempo.

Sin embargo, la tecnología, en el contexto latinoamericano y centroamericano aumenta la brecha de desigualdad y marginación ya que una pequeña proporción de la juventud se conserva superconectada y otra de mayor proporción se mantiene precarizada socialmente.

La generación de personas nacidas después del año 2010 vive en la globalización, adaptan elementos de la globalización y los modifican a su localidad, por ello se denominan generación Glocal.

Este enfoque centrado en los jóvenes reconoce y comprende los cambios en las formas de participación que introducen elementos culturales propios de la generación y los adaptan a su participación social.

Ahora bien, cabe preguntarse ílos jóvenes, en especial en el contexto centroamericano, se auto identifican cómo generación Glocal? ¿Qué características poseen estos jóvenes? ¿Cuál es el nivel de acceso a la tecnología de los jóvenes actuales? ¿Cómo la utilizan? ¿Qué segmentos de la población joven son excluidos? ¿ De qué manera las redes sociales influyen en la auto identificación de los jóvenes? ¿Qué pasa con los jóvenes que tienen acceso limitado a las tecnologías? ¿Son jóvenes Glocales? ¿Qué impacto, está provocando en los jóvenes el confinamiento obligado por la pandemia del COVID-19? ¿Se ha modificado el acceso a las tecnologías? 


\section{CONCLUSIONES}

Al concluir el proceso de revisión bibliográfica sobre el tema de juventudes se puede confirmar que es un concepto en desarrollo, el cual dependerá del proceso de transformación del mundo o en palabras de Bourdieu del habitus en que se encuentren los jóvenes. El estudio de la juventud desde la perspectiva generacional nos permite comprender a los jóvenes como se auto y hetero perciben, cómo han adaptado la tecnología a su cotidianidad, cómo asumen lo que ocurre en el mundo y lo expresan en la localidad.

La actual generación de jóvenes, es llamada "generación Glocal", le ha tocado vivir en el mundo globalizado, con dinámicas propias que imprimen un sello particular a sus experiencias en lo cotidiano, en lo Glocal y las expresiones en lo público y en lo privado.

\section{REFERENCIAS BIBLIOGRÁFICAS}

Acevedo, Á., \& Correa, A. (2016). Jóvenes: historia Glocal de un concepto en evolución. Revista Katharsis, 197-220.

Augé, M. (2009). Sobremodernidad. Del mundo de hoy al mundo de mañana. www.memoria.com. Obtenido de Augé: http://www.memoria. com.mx/129/auge.htm

Bauman, Z. (2007). Entre nosotros, las generaciones. En J. Larrosa, Entre nosotros, sobre la convivencia entre generaciones (págs. 101-128). Barcelona: Fundació Viure i Conviure y Caixa Catalunya.

Bourdieu, P. (1984/2003). Cuestiones de sociología. Madrid: Editorial Istmo. Bourdieu, P. (1990). La juventud no es más que una palabra. En P. Bourdieu, Sociología y cultura (págs. 163-173). México: Grijalbo.

Brito Lemus, R. (2002). Identidades juveniles y praxis divergente: acerca de la conceptualización de juventud. En A. Nateras Domínguez, Jóvenes, culturas e identidades urbanas (pág. 169). México: Universidad Autónoma Metropolitana, Unidad Iztapalapa.

Centro de Estudios de Guatemala, CEG. (2012). Las múltiples violencias que afectan a las juventudes. Guatemala.

Chaves, M. (2006). Investigaciones sobre juventudes en Argentina: estado del arte en ciencias sociales. Buenos Aires: Universidad Nacional de San Martín.

Dávila, O. (2004). Adolescencia y juventud: de las nociones a los abordajes. Última Década, 83-104.

de la Torre, M. (2020). COVID-19: La sociedad cautiva en el espacio global . Estudios de la Paz y el Conflicto, Revista Latinoamericana, 150-161. 
Doutor, C. (2016). Um olhar sociologico sobre os conceitos de juventude e de prácticas culturais: perspetivas e reflexoes. Última Década, 159-174.

Feixa, C. (2018). Culturas juveniles como perspectiva para analizar juventudes (1993-2018). Última Década, 89-105.

Feixa, C., \& Nilan, P. (2009). ¿Una juventud global? Identidades hibridas, mundos plurales. Educación Social, 75-89.

Fondo de las Naciones Unidas para la Infancia, UNICEF. (2006). Convención sobre los Derechos del Niño. Madrid: Nuevo Siglo.

Gabsi, Z. (2020). Tunisian youth as drivers of socio-cultural and political changes: glocality and effacement of cultural memory? British Journal of Middle Eastern Studies, 1-22.

Giddens, A. (1990). The Consequences of Modernity. Standfor: Stanford University Press.

Homobono, J. (2019). Glocalización: síntesis de lo global y lo local. Zainak. Cuadernos de antropología- etnografía, 19-54.

Krauskopf, D. (2015). Los marcadores de juventud: la complejidad de las edades. Última década, 115-128.

Mannheim, K. (1928/2007). El problema de las generaciones. REIS, 193242.

Martín-Barbero, J. (2014). Nuevas visibilidades de lo cultura y nuevos regímenes de lo estético. La Puerta, 106-119.

Muñoz, G. (2010). De las culturas juveniles a las ciberculturas del siglo XXI. Educación y Ciudad, 19-32.

Organización de las Naciones Unidas para la Educación, la Ciencia y la Cultura, UNESCO. (1985). Año Internacional de la Juventud, 1985. París: UNESCO.

Organización de las Naciones Unidas, ONU. (2009). Resolución A/R/64/164. Año Internacional de la Juventud, 2010: diálogo y comprensión mutua. Ginebra: ONU.

Organizaciones de las Naciones Unidas, ONU. (1979). Resolución A/R/34/151. Año Internacional de la Juventud: participación, desarrollo y paz. Ginebra: ONU.

Ortega y Gasset, J. (1951). Obras Completas, Tomo V, En torno a Galileo (1933-1941). Madrid: Revista de Occidente.

Pérez Islas, R. (2000). Umbrales. Cambios culturales, desafíos nacionales y juventud. Medellín: Corporación Región.

Piaget, J., \& Inhelder, B. (1969/1997). Psicología del niño. Madrid: Ediciones Morata.

Programa de Naciones Unidas para el Desarrollo, PNUD. (2011). Informe Nacional de Desarrollo Humano, 2011. Las juventudes construyendo Nicaragua. Managua: PNUD.

Programa de Naciones Unidas para el Desarrollo, PNUD. (2018). Informe sobre Desarrollo Humano, El Salvador 2018. iSoy joven! ¿Y ahora qué? La Libertad: Impresos Múltiples.

Ramírez, F. (2020). Juventud y movimientos sociales: reflexiones sobre la generación glocal latinoamericana. Revista Argentina de Estudios de Juventud, 2-18. 
Reguillo, R. (2000). Identidades culturales y espacio público: un mapa de los silencios. Diálogos de la comunicación, 74-86.

Reguillo, R. (2003). Las culturas juveniles: un campo de estudio. Revista Brasileira da Educacao, 103-118.

Reguillo, R. (2008). Jóvenes imaginados: la disputa por la representación (contra la esencialización). Punto cero, 7-14.

Reguillo, R. (2010). Los jóvenes en México. México: Fondo de Cultura Económica.

Reguillo, R. (2013). Jóvenes en la encrucijada contemporánea: en busca de un relato futuro. Culturas juveniles emergentes (págs. 137-151). Guadalajara: UNAM.

Robertson, R. (2000). Glocalización:tiempo-espacio y homogeneidad heterogeneidad. Zona Abierta.

Rueda Ortíz, R. (2003). Para una pedagogía del hipertexto: una teoría entre la deconstrucción y la complejidad (Tesis). Palma de Mallorca: Universidad de las Islas Baleares.

Sedda, F. (2015). Forms of the World: Roots, Histories, and Horizons of the glocal. En R. Robertson, European Glocalization in Global Context (págs. 225). Hampshire: Macmillan Distribution Ltd. 